\title{
Incremental Health Care Resource Utilization and Economic Burden of Venous Thromboembolism Recurrence from a U.S. Payer Perspective
}

\author{
J. Lin, PhD; R. Preblick, PharmD, MPH; M. Lingohr-Smith, PhD; and W.J. Kwong, PharmD, PhD
}

\begin{abstract}
BACKGROUND: The third leading cause of cardiovascular-associated death, venous thromboembolism (VTE), represents a significant health care and economic burden. Although the burden of a one-time VTE event has been assessed, there are limited data regarding the burden of VTE recurrence.

OBJECTIVE: To assess the rate and predictors of VTE recurrence within 1 year in the United States and evaluate the incremental health care resource utilization and costs associated with such VTE recurrences.
\end{abstract}

METHODS: Patients ( $\geq 18$ years) diagnosed with deep vein thrombosis and/ or pulmonary embolism between January 1,2008 , and December 31,2010 , were identified from the Truven Health Analytics MarketScan Commercial and Medicare databases. The earliest VTE diagnosis was defined as the index VTE event. Patients were required to have 12 months of continuous insurance coverage before (baseline period) and after (follow-up period) the index event. Patients were further required to have initiated anticoagulant usage within 30 days of the index VTE event and have at least 30 days of treatment. The incidence of recurrent VTE, defined as a hospitalization or emergency room (ER) visit with a VTE diagnosis in the follow-up period, was determined for the commercially insured and Medicare populations separately. A proportional hazards model was used to assess the predictors of time to VTE recurrences. All cause and VTE-related health care resource utilization including hospitalizations, length of stay, outpatient medical service claims, and outpatient pharmacy claims were assessed along with the associated costs incurred during the 30-day and 12-month post-index event periods. Commercially insured and Medicare patients with and without recurrent VTE were evaluated and compared separately. Generalized linear models were used to further assess the incremental cost burden of recurrent VTE.

RESULTS: Among the commercially insured population, 29,275 patients were diagnosed with VTE and received anticoagulant therapy. A recurrence of VTE associated with a hospitalization or ER visit occurred within 12 months of the index VTE in $15.4 \%$ of patients with a mean time to recurrence of 74.1 days. Among the Medicare insured population $(n=14,509)$, $11.4 \%$ of patients experienced another VTE with a mean time to recurrence of 115.6 days. A consistent predictor of VTE recurrence across both populations was greater comorbidity as indicated by Charlson Comorbidity Index scores. Among commercially insured VTE patients, total payments for health care resource utilization for all causes, including inpatient, outpatient medical services, and outpatient pharmacy use were higher for patients with a recurrent VTE relative to those without a recurrent VTE $(\$ 82,110$ [\$106,918] vs. $\$ 36,918$ [\$54,852], $P<0.001)$. The primary driver for the higher health care payments was greater use of inpatient care. Total payments for VTE-related resource use was also greater for patients with a VTE recurrence $(\$ 38,591[\$ 51,479]$ vs. $\$ 15,123[\$ 22,186], P<0.001)$ with the majority $(62.9 \%)$ attributed to care that took place within 30 days of the index VTE. After adjustment for key patient characteristics, VTE recurrence was associated with 2.2-fold and 3.0-fold higher post-index health care payments for all causes and for VTE-related claims, respectively. Similar results were observed for the Medicare population.
CONCLUSIONS: VTE recurrence associated with a hospitalization or ER visit is associated with substantial health care resource utilization, which is primarily inpatient care undergone within the first 30 days following an initial VTE event. Thus, a sizeable portion of the economic burden of recurrent VTE is also incurred during this short period of time following an initial VTE event. Given that rates of VTE recurrence were high among patients identified as having received anticoagulant treatment, strategies to improve anticoagulation therapy among VTE patients in addition to other preventative measures are needed to lessen the health care and economic burdens of VTE.

\section{J Manag Care Pharm. 2014;20(2):174-86}

Copyright $\odot 2014$, Academy of Managed Care Pharmacy. All rights reserved.

\section{What is already known about this subject}

- The third leading cause of cardiovascular-associated death, venous thromboembolism (VTE), represents a significant health care and economic burden.

- The annual average number of hospitalizations attributed to VTE is more than 500,000 .

- Average total annual hospitalization costs (1998-2004) for VTE patients have been estimated to range between $\$ 7,594$ and $\$ 27,909$, depending on the type of event and whether it was a primary or secondary diagnosis.

- Among hospitalized VTE patients, direct medical costs for VTE per patient per year are substantial and result not only from the initial VTE hospitalization event, but also from a high rate of hospital readmission for a subsequent VTE (5.3\%-14.3\%).

\section{What this study adds}

- Even with anticoagulant treatment, the incidence of VTE recurrence associated with a hospitalization or emergency room visit ranged from $11.4 \%$ to $15.4 \%$, with the majority of recurrences occurring within 30 days of the initial VTE.

- The likelihood of VTE recurrence appears to be most strongly related to comorbidities.

- Among both commercially and Medicare insured VTE patients, total payments for VTE-related health care resource utilization, including inpatient, outpatient medical services, and outpatient pharmacy use, are 3.0-fold and 3.4-fold higher, respectively, for patients with a recurrence of VTE relative to those without a recurrent VTE.

- The primary driver for the higher health care costs is a greater use of inpatient care.

- Reducing VTE recurrence is critical to lessen the health care and economic burdens of VTE. 
$\mathrm{V}$ enous thromboembolism (VTE) is a coagulation disorder that predisposes individuals to clot formation in the venous system, primarily in the veins of legs, called deep vein thrombosis (DVT). When a clot breaks free, it can travel to the lungs causing pulmonary embolism (PE), a sequelae of VTE that is directly associated with 5\% to $10 \%$ of all in-hospital deaths. ${ }^{1-3}$ The incidence of VTE increases with age with the Centers for Disease Control and Prevention reporting average annual rates of VTE ranging from 60 per 100,000 population for persons aged 18-39 years to 1,134 per 100,000 for persons aged $\geq 80$ years. ${ }^{4}$ Mahan et al. (2012) estimated that, in 2011 U.S. dollars, the annual cost of VTE ranges between $\$ 13.5$ and $\$ 27.2$ billion. ${ }^{5}$ The substantial burden to the health care system and the high frequency of preventable cases have prompted the Surgeon General and the U.S. Department of Health and Human Services (Partnership for Patients) to elicit a call to action focused on reversing the projected trends of VTE. ${ }^{6,7}$

The treatment goals of VTE therapy are to stop clot propagation and to prevent thrombus recurrence and PE. ${ }^{8}$ The American College of Chest Physicians recommends initial treatment for DVT or PE with parenteral low-molecular-weight heparin (LMWH) or anticoagulation with rivaroxaban and anticoagulation therapy (such as a vitamin $\mathrm{K}$ antagonist, LMWH, rivaroxaban, or dabigatran) for 3 months or longer depending on bleeding risk and whether the event was provoked, unprovoked, or associated with active cancer. ${ }^{9}$

The health care and economic burdens of VTE are not only related to diagnosis and treatment of the initial event, but also to VTE recurrence..$^{10-12}$ Spyropoulos and Lin (2007) reported that hospital readmission rates of hospitalized VTE patients were between $5.3 \%$ and $14.3 \%$ by 1 year. ${ }^{10}$ It is important to better understand the overall health care and economic burdens of recurrent VTE among both inpatient- and outpatienttreated VTE patients and to define populations at high risk for VTE recurrence in order to potentially improve the quality of care for VTE patients. ${ }^{6,7}$ To that end, this study's purpose was to evaluate the rate and predictors of VTE recurrences among both inpatient- and outpatient-treated VTE patients and determine the incremental burden of health care resource utilization and costs among patients with VTE recurrence who have commercial or Medicare insurance coverage in the United States.

\section{Methods}

\section{Data Source}

Patient-level data were extracted from the Truven Health Analytics MarketScan Commercial and Medicare databases from January 1, 2007, to December 31, 2011. The MarketScan Commercial Claims and Encounters database and Medicare Supplemental database capture person-specific health care use, expenditures, and enrollment in inpatient, outpatient, and prescription drug services for millions of beneficiaries residing in multiple states across the United States. Data from individual patients are integrated from all providers of care, maintaining all health care utilization and cost connections at the patient level. The MarketScan Medicare Supplemental database contains the Medicare covered, employer-paid, and any out-of-pocket portions paid for the health care encounter. In compliance with the Health Insurance Portability and Accountability Act of 1996 (HIPAA), the databases consist of fully de-identified data sets, with synthetic identifiers applied to patient-level and provider-level data to protect the identities of both the patients and data contributors.

\section{Study Population}

Patients who had at least 1 inpatient claim with a primary or secondary VTE diagnosis or 2 outpatient claims (including emergency room (ER) visit) on 2 separate dates for VTE diagnosis as identified by International Classification of Diseases, Ninth Revision, Clinical Modification (ICD-9-CM) codes for VTE between January 1, 2008, and December 31, 2010, were eligible for inclusion in the study. The following ICD-9-CM codes were used to identify patients who had DVT: 451.1, 451.2, 451.8, 451.9, 453.2, 453.4, 453.8, and 453.9. The ICD-9-CM code of 415.1 was used to identify patients who had a PE. The first VTE diagnosis to occur during the index VTE identification period was defined as the index VTE event, and the type of VTE (i.e., DVT, PE, or DVT/PE) was determined on the first day of the VTE diagnosis. Two outpatient claims were required to maximize the likelihood that a medical visit associated with VTE treatment did occur and minimize the risk of misidentifying an outpatient visit with a "rule-out" VTE diagnosis as an index event. To further increase the likelihood that the identified VTE diagnoses were for VTE events, all VTE patients were required to have evidence of VTE pharmacological treatment, defined as treatment with unfractionated heparin (UFH), LMWH, warfarin, or fondaparinux for a duration of $\geq 30$ days and initiated within 30 days of the index VTE event. All patients within the study populations were required to be $\geq 18$ years at the index VTE event and have 12 months of continuous medical and prescription benefit coverage prior to (baseline period) and after the index VTE event (follow-up period).

\section{VTE Recurrence Definition}

During the follow-up period, recurrence of VTE was evaluated for the commercially and Medicare insured populations. A recurrence of VTE was defined as having a hospital admission or ER visit identified by medical claims associated with a primary or secondary diagnosis of DVT and/or PE that occurred more than 2 days after the index VTE event (ICD-9-CM codes as previously mentioned). The 2-day period was used to rule out hospital admissions related to treatment of the index 
VTE event. For both the commercially and Medicare insured populations, patients were grouped into one of 2 cohorts; one composed of patients without a recurrent VTE during the 12-month follow-up period and the second composed of patients who experienced a VTE recurrence during the followup period. The time to first recurrent VTE for patients having been identified as having a recurrence was summarized.

\section{Baseline Demographics and Clinical Characteristics}

Patient demographics consisting of age, gender, and U.S. region of residence along with type of health plan were collected. Clinical characteristics consisting of index VTE type (i.e., DVT only, PE only, DVT/PE), setting of initial care (inpatient vs. outpatient), Deyo-Charlson Comorbidity Index (CCI), comorbidities, and Elixhauser Comorbidity Index (EI) were assessed based on data collected during the 12 months prior to the index event. History of hospitalization and/or surgery 30 days prior to the initial VTE were determined for all patients within the commercially and Medicare insured populations. The CCI is a widely used measurement that is predictive of the likelihood of 1-year and 10-year mortality based on the presence or absence of 19 comorbid conditions and their associated assigned weights. ${ }^{13}$ The more recently developed EI, ${ }^{14}$ a comorbidity index based on the presence or absence of 30 comorbid conditions, was also measured for each patient within the commercially and Medicare insured populations.

\section{General Statistical Analyses}

Descriptive statistics were used to summarize and compare the demographic and clinical characteristics of the study cohorts within the commercially and Medicare insured populations. Means, standard deviations (SD), and medians were reported for continuous data, and counts and percentages were reported for categorical data. For comparisons of health care utilization and associated costs between patients with and without recurrent VTE, t-tests and chi-square tests were used for continuous and categorical variables, respectively. A $P$ value of 0.05 was used to determine statistical significance. All statistical analyses were carried out using SAS 9.2 (Cary, NC).

\section{Patient Characteristics that Impact VTE Recurrence}

A Cox proportional hazards model, in which the time to VTE recurrence was the dependent variable, was conducted. Predictor covariates included age, gender, VTE type, setting of VTE diagnosis (inpatient or outpatient), CCI score, and U.S. region of residence.

\section{Comparison of Health Care Resource Utilization and Payments at the Unadjusted Level: Patients with VTE Recurrence Versus Patients Without VTE Recurrence}

Hospitalizations, including total length of stay (LOS), claims for outpatient medical services (all outpatient medical services and just those for ER visits), and outpatient prescription claims were evaluated for each patient in the study populations during a 30-day period following the index VTE event and for the entire 12-month follow-up period. Inpatient, outpatient medical services, and outpatient pharmacy resource utilization categories were grouped into all-cause (i.e., health care use for any reason) and VTE-related, which included all claims associated with a diagnosis of VTE. VTE-related outpatient pharmacy use consisted of prescribed anticoagulant use. All cost values in the study represent the health care payment amount. The health care payments made by health plans and the overall total reimbursed payments from health plans, patients and/or other third-party payers to the hospital for covered services provided during an admission were measured and reported. Health care resource utilization and associated costs were then compared among the study cohorts of patients with and without VTE recurrence. Results were reported separately for the commercially and Medicare insured populations.

\section{Comparison of Adjusted Total Health Care Payments: Patients with VTE Recurrence Versus Patients Without VTE Recurrence}

Generalized linear models with log transformation for cost data and gamma distribution as the link function were used to evaluate the impact of VTE recurrence on total payments, while controlling for key patient characteristics. Payments included those for health care resource utilization for any reason and those that were VTE-related. Absolute cost differences and cost ratios of total payments within 30 days and 12 months post-index VTE event were reported. Covariates used in the regression models were age, gender, VTE type, setting of initial VTE diagnosis (inpatient or outpatient), CCI score, and U.S. region of residence. We additionally carried out a sensitivity multivariable regression analysis in which additional covariates were added. These additional covariates were health plan types and comorbidities including cancer, congestive heart failure, chronic obstructive pulmonary disease/pulmonary diseases, severe infectious diseases, stroke/transient ischemic attack, acute coronary syndrome, hypertension, and diabetes.

\section{Results}

\section{Study Population}

Among the commercially insured, 29,275 patients with an index VTE event were identified during the study selection period (Figure 1). Among this study population, the recurrent VTE cohort consisted of 4,498 (15.4\%) patients. The mean time to VTE recurrence was 74.1 days in this cohort. Among the Medicare insured, 14,509 patients with an initial VTE event were identified during the study selection period (Figure 1). The recurrent VTE cohort within this Medicare population consisted of 1,655 (11.4\%) patients. The mean time to VTE recurrence was 115.6 days in this cohort. 


\section{FIGURE 1 Flowchart of the Selection of Study Populations}

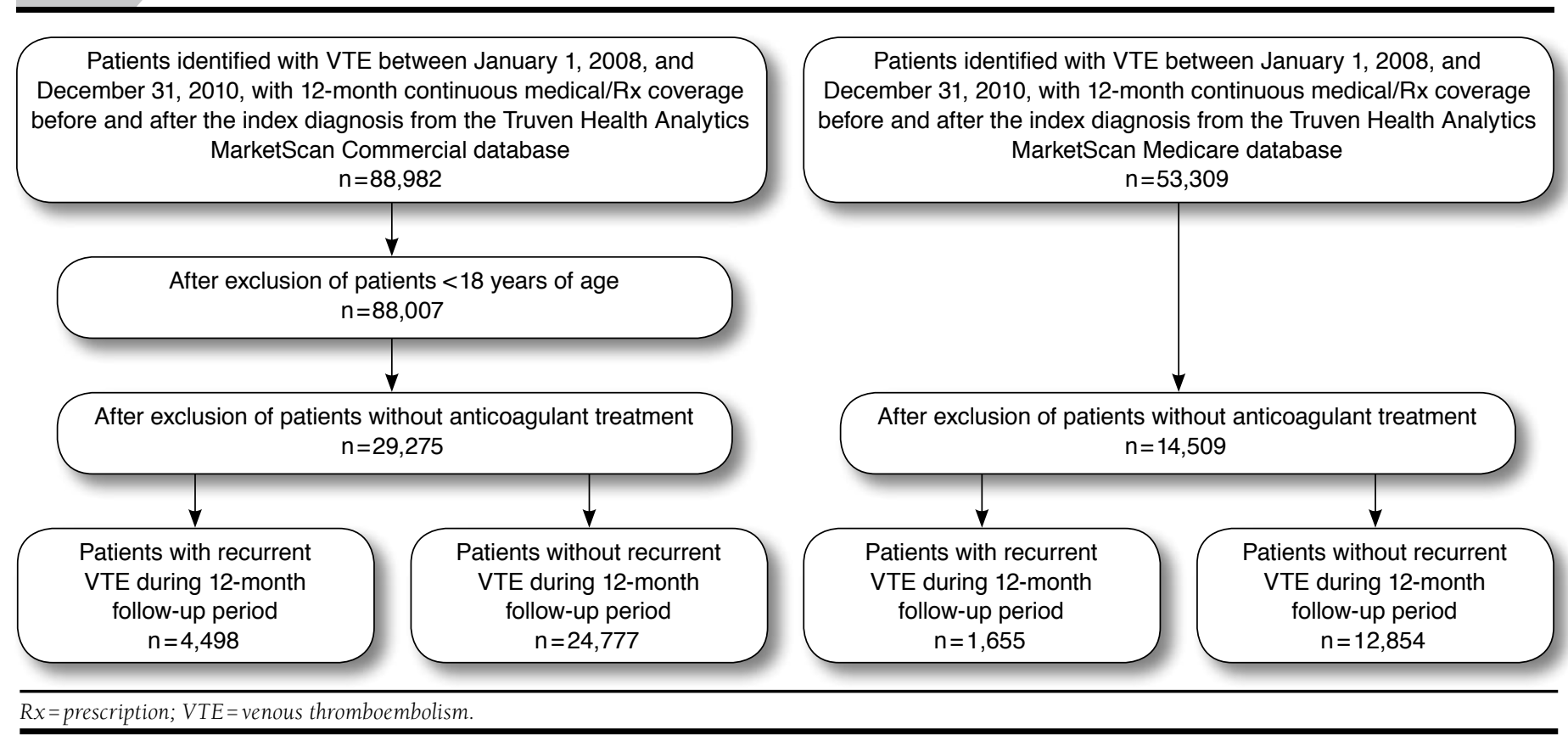

\section{Baseline Demographics and Clinical Characteristics}

Baseline demographics for the commercially and Medicare insured populations are presented in Table 1. For the commercially insured population, the mean age was slightly higher for patients without a recurrent VTE (48.5 vs. 49.9 years, $P<0.001)$. The VTE recurrence cohort had a lower proportion of male patients than the cohort without VTE recurrence (48.1\% vs. $51.5 \%, P<0.001)$. For the Medicare insured population, mean ages ( 77.0 vs. 76.8 years, $P=0.307)$ and proportion of male patients were similar (45.1\% vs. $46.2 \%, P=0.370$ ) for patients with and without VTE recurrence.

Baseline clinical characteristics for the commercially and Medicare insured populations are presented in Table 2. Among the commercially insured population, DVT was the most common index VTE event type for patients with and without recurrent VTE ( $59 \%$ for both cohorts), followed by PE only $(\sim 25 \%)$, and DVT/PE (15\%-16\%). The majority of index VTE events were treated in the inpatient setting (58\% with recurrent VTE and $60 \%$ without recurrent VTE). Mean CCI (1.5 vs. 1.2, $P<0.001)$ and EI $(2.7$ vs. $2.4, P<0.001)$ scores at baseline were greater for patients with VTE recurrence in comparison with patients without VTE recurrence. The proportion of patients with a hospitalization 30 days prior to the index VTE event was higher for patients with a VTE recurrence (14.5\% vs. $11.8 \%$, $P<0.001)$. Among the commercially insured population with recurrent VTE, significantly more patients had comorbidities of severe infectious diseases (29.3\% vs. $24.7 \%, P<0.001)$, cancer
(17.5\% vs. $13.3 \%, P<0.001$ ), chronic obstructive pulmonary disease/pulmonary diseases ( $15.7 \%$ vs. $13.9 \%, P=0.001)$, and congestive heart failure (5.1\% vs. $4.1 \%, P=0.003)$.

Clinical characteristics of the index VTE event among the Medicare insured population were similar to the commercially insured population. DVT was the most frequent index VTE event type with a greater proportion of patients with recurrent VTE having this event type than patients without recurrent VTE $(63.0 \%$ vs. $56.3 \%, P<0.001)$. There were also fewer patients with an index PE event in the recurrent VTE cohort than the no recurrent VTE cohort (24.2\% vs. $30.0 \%$, $P<0.001)$. A lower proportion of patients who had a VTE recurrence were treated in the inpatient setting for their index VTE event in comparison with patients who did not have a recurrent VTE ( $51.4 \%$ vs. $58.6 \%, P<0.001)$. Mean CCI (2.6 vs. 2.3, $P<0.001)$ and EI $(3.9$ vs. 3.6, $P<0.001)$ scores at baseline were greater for patients with VTE recurrence versus those without a recurrence. Among the Medicare insured population with recurrent VTE, significantly more patients had severe infectious diseases ( $36.4 \%$ vs. $31.3 \%, P<0.001)$, cancer $(32.8 \%$ vs. $28.6 \%, P=0.001)$, and chronic obstructive pulmonary disease/ pulmonary diseases $(27.5 \%$ vs. $24.7 \%, P=0.013)$.

\section{Outpatient Anticoagulant Use Among Study Populations}

Inpatient use of anticoagulation therapy could not be evaluated because the data are not captured in the MarketScan databases. In the outpatient setting, the vast majority of commercially insured patients received warfarin for their index VTE events 
Incremental Health Care Resource Utilization and Economic Burden of

Venous Thromboembolism Recurrence from a U.S. Payer Perspective

TABLE 1 Patient Demographics of Commercially and Medicare Insured Study Populations

\begin{tabular}{|c|c|c|c|c|c|c|c|c|c|c|}
\hline \multirow[b]{3}{*}{ Mean [SD] age in years } & \multicolumn{4}{|c|}{ Commercial Recurrent VTE } & \multirow{3}{*}{$\begin{array}{r}P \text { Value } \\
<0.001\end{array}$} & \multicolumn{4}{|c|}{ Medicare Recurrent VTE } & \multirow{3}{*}{$\frac{P \text { Value }}{0.307}$} \\
\hline & \multicolumn{2}{|c|}{ Yes $(n=4,498)$} & \multicolumn{2}{|c|}{ No $(n=24,777)$} & & \multicolumn{2}{|c|}{ Yes $(n=1,655)$} & \multicolumn{2}{|c|}{ No $(n=12,854)$} & \\
\hline & 48.5 & [11.3] & 49.9 & {$[10.4]$} & & 77.0 & {$[7.3]$} & 76.8 & {$[7.2]$} & \\
\hline Age group (years) \% (n) & & & & & $<0.001$ & & & & & 0.073 \\
\hline $18-29$ & 7.6 & $(343)$ & 4.8 & $(1,199)$ & & 0.0 & $(0)$ & 0.0 & $(0)$ & \\
\hline $30-39$ & 13.8 & $(621)$ & 12.0 & $(2,984)$ & & 0.0 & (1) & 0.0 & $(0)$ & \\
\hline $40-49$ & 24.2 & $(1,088)$ & 25.4 & $(6,290)$ & & 0.0 & (1) & 0.0 & $(0)$ & \\
\hline $50-59$ & 36.4 & $(1,635)$ & 37.3 & $(9,246)$ & & 0.5 & $(62)$ & 0.6 & $(10)$ & \\
\hline $60-64$ & 18.0 & $(811)$ & 20.4 & $(5,058)$ & & 0.8 & (98) & 1.5 & $(25)$ & \\
\hline $65-69$ & 0.0 & $(0)$ & 0.0 & $(0)$ & & 16.6 & $(2,128)$ & 16.0 & $(265)$ & \\
\hline $70-74$ & 0.0 & $(0)$ & 0.0 & $(0)$ & & 22.8 & $(2,933)$ & 21.6 & $(357)$ & \\
\hline $75-79$ & 0.0 & $(0)$ & 0.0 & $(0)$ & & 23.6 & $(3,038)$ & 23.0 & $(380)$ & \\
\hline$\geq 80$ & 0.0 & $(0)$ & 0.0 & $(0)$ & & 35.7 & $(4,593)$ & 37.3 & (618) & \\
\hline Gender \% (n) & & & & & $<0.001$ & & & & & 0.370 \\
\hline Male & 48.1 & $(2,162)$ & 51.5 & $(12,753)$ & & 45.1 & $(746)$ & 46.2 & $(5,944)$ & \\
\hline Female & 51.9 & $(2,336)$ & 48.5 & $(12,024)$ & & 54.9 & (909) & 53.8 & $(6,910)$ & \\
\hline Region \% (n) & & & & & 0.325 & & & & & $<0.001$ \\
\hline Northeast & 12.8 & $(577)$ & 12.6 & $(3,120)$ & & 15.3 & $(253)$ & 12.5 & $(1,600)$ & \\
\hline North Central & 30.0 & $(1,350)$ & 31.5 & $(7,808)$ & & 39.3 & $(651)$ & 42.0 & $(5,395)$ & \\
\hline South & 37.1 & $(1,670)$ & 36.1 & $(8,945)$ & & 22.2 & $(368)$ & 27.5 & $(3,533)$ & \\
\hline West & 18.2 & $(820)$ & 18.2 & $(4,499)$ & & 22.4 & $(370)$ & 17.3 & $(2,228)$ & \\
\hline Unknown & 1.8 & $(81)$ & 1.6 & $(405)$ & & 0.8 & (13) & 0.8 & (98) & \\
\hline Health plan type \% (n) & & & & & 0.018 & & & & & $<0.001$ \\
\hline Comprehensive & 3.7 & $(165)$ & 3.8 & $(935)$ & & 41.1 & $(680)$ & 46.5 & $(5,981)$ & \\
\hline EPO & 1.2 & $(55)$ & 1.4 & $(339)$ & & 0.0 & $(0)$ & 0.0 & (3) & \\
\hline $\mathrm{HMO}$ & 18.5 & $(830)$ & 16.9 & $(4,174)$ & & 20.3 & $(336)$ & 11.5 & $(1,479)$ & \\
\hline POS & 9.3 & $(417)$ & 10.0 & $(2,474)$ & & 3.1 & $(52)$ & 3.1 & $(402)$ & \\
\hline POS w/capitation & 0.8 & (35) & 0.5 & $(135)$ & & 0.0 & $(0)$ & 0.0 & (3) & \\
\hline $\mathrm{PPO}$ & 59.9 & $(2,692)$ & 59.8 & $(14,809)$ & & 33.7 & (558) & 36.7 & $(4,713)$ & \\
\hline CDHP & 3.7 & $(167)$ & 4.1 & $(1,013)$ & & 0.4 & (6) & 0.5 & $(63)$ & \\
\hline Missing/unknown & 3.1 & $(137)$ & 3.6 & $(898)$ & & 1.4 & $(23)$ & 1.6 & $(210)$ & \\
\hline
\end{tabular}

$\mathrm{CDHP}=$ consumer driven health plan; $E P O=$ exclusive provider organization; $H M O=$ health maintenance organization; $P O S=$ point of service; $P P O=$ preferred provider organization; $S D=$ standard deviation; VTE = venous thromboembolism.

(96.2\% of patients with VTE recurrence and $97.5 \%$ of patients without VTE recurrence). Most patients were also treated with an LMWH $(70.5 \%$ of patients with VTE recurrence and 62.5\% of patients without VTE recurrence). In the outpatient setting, the majority of Medicare insured patients were also treated with warfarin (97\%-98\%) for their index VTE events.

\section{Incidence of Specific VTE Events and Time to Recurrence}

Figure 2a presents the cumulative 12-month incidence of VTE recurrence among commercially insured patients by index event type. Among commercially insured patients who experienced a VTE recurrence, DVT was the most common recurrent event (experienced by $58.8 \%$ of patients, with a mean time to recurrence of 70.5 days) followed by PE (experienced by $24.8 \%$ of patients, with a mean time to recurrence of 76.4 days). A combined DVT/PE type of recurrence was identified in $16.4 \%$ of patients experiencing a recurrent event with a mean time to recurrence of 83.5 days. Among patients with VTE recur- rences, the majority of recurrences occurred within the first month after the index VTE, with $58.3 \%$ of such recurrences occurring within the first month among VTE recurrence patients who had DVT as their index event, 57.2\% of such recurrences occurring among VTE recurrence patients who had PE as their index event, and 51.4\% of such recurrences occurring among VTE recurrence patients who had DVT/PE as their index event (see Figure 3a).

Figure $2 \mathrm{~b}$ presents the cumulative 12-month incidence of VTE recurrence among Medicare insured patients within 1 year of the index VTE. Similar to results of commercially insured patients, the majority of Medicare insured patients experiencing a recurrence had a DVT $(63.0 \%)$ with a mean time to recurrence of 110.3 days. PE (24.2\%) was the second most frequent type of recurrence with a mean time to recurrence of 116.4 days. A combined DVT/PE (12.7\%) recurrent event was the least frequent type of VTE with a mean time of recurrence of 140.2 days. The mean times to recurrence for 
Incremental Health Care Resource Utilization and Economic Burden of

Venous Thromboembolism Recurrence from a U.S. Payer Perspective

TABLE 2 Patient Clinical Characteristics of Commercially and Medicare Insured Study Populations

\begin{tabular}{|c|c|c|c|c|c|c|}
\hline & \multicolumn{2}{|c|}{ Commercial Recurrent VTE } & \multirow[b]{2}{*}{$P$ Value } & \multicolumn{2}{|c|}{ Medicare Recurrent VTE } & \multirow[b]{2}{*}{$P$ Value } \\
\hline & Yes $(n=4,498)$ & No $(n=24,777)$ & & Yes $(n=1,655)$ & No $(n=12,854)$ & \\
\hline & & & & & & \\
\hline DVT only & $58.9 \quad(2,647)$ & $59.0(14,619)$ & & $63.0 \quad(1,043)$ & $56.3 \quad(7,232)$ & \\
\hline PE only & $24.8 \quad(1,115)$ & $25.7 \quad(6,358)$ & & $24.2 \quad(401)$ & $30.0 \quad(3,859)$ & \\
\hline DVT/PE & $16.4 \quad(736)$ & $15.3(3,800)$ & & $(211)$ & $13.7 \quad(1,763)$ & \\
\hline Index VTE treatment setting \% (n) & & & 0.041 & & & $<0.001$ \\
\hline Inpatient & $58.4 \quad(2,625)$ & $59.9(14,846)$ & & $(850)$ & $58.6 \quad(7,526)$ & \\
\hline Outpatient & $41.6 \quad(1,873)$ & $40.1 \quad(9,931)$ & & $(805)$ & $41.5 \quad(5,328)$ & \\
\hline Mean [SD] Charleson Comorbidity Index & {$[2.4]$} & {$[2.0]$} & $<0.001$ & {$[2.6]$} & {$[2.4]$} & $<0.001$ \\
\hline CCI group \% (n) & & & $<0.001$ & & & $<0.001$ \\
\hline 0 & $48.3 \quad(2,174)$ & $53.4(13,237)$ & & $(341)$ & $23.9 \quad(3,074)$ & \\
\hline $1-2$ & $32.3 \quad(1,454)$ & $32.2 \quad(7,982)$ & & $(667)$ & $41.8 \quad(5,372)$ & \\
\hline $3-4$ & $(432)$ & $7.9 \quad(1,966)$ & & $(356)$ & $21.3 \quad(2,735)$ & \\
\hline$\geq 5$ & $(438)$ & $6.4 \quad(1,592)$ & & $(291)$ & $13.0 \quad(1,673)$ & \\
\hline Mean [SD] Elixhauser Comorbidity Index & {$[2.2]$} & $2.4 \quad[2.0]$ & $<0.001$ & {$[2.2]$} & {$[2.1]$} & $<0.001$ \\
\hline \multicolumn{7}{|l|}{ Comorbidities \% (n) } \\
\hline Cancer & $(786)$ & $13.3(3,299)$ & $<0.001$ & $(542)$ & $28.6 \quad(3,682)$ & $<0.001$ \\
\hline Congestive heart failure & $(231)$ & $4.1 \quad(1,027)$ & 0.003 & $(274)$ & $15.1 \quad(1,946)$ & 0.132 \\
\hline COPD/pulmonary diseases & $(708)$ & $13.9 \quad(3,448)$ & 0.001 & $(455)$ & $24.7 \quad(3,171)$ & 0.013 \\
\hline Severe infectious diseases & $29.3 \quad(1,318)$ & $24.7 \quad(6,127)$ & $<0.001$ & $(602)$ & $31.3 \quad(4,026)$ & $<0.001$ \\
\hline Stroke/TIA & $2.8 \quad(127)$ & $(661)$ & 0.553 & $(156)$ & $8.5 \quad(1,098)$ & 0.228 \\
\hline Acute coronary syndrome & $(122)$ & $(617)$ & 0.382 & $(89)$ & $(783)$ & 0.250 \\
\hline Hypertension & $38.9 \quad(1,748)$ & $37.6 \quad(9,305)$ & 0.096 & $67.3 \quad(1,114)$ & $65.0 \quad(8,360)$ & 0.068 \\
\hline Diabetes & $15.2 \quad(684)$ & $14.1 \quad(3,492)$ & 0.050 & $25.1 \quad(416)$ & $23.9 \quad(3,067)$ & 0.253 \\
\hline Hospitalization 30 days prior $\%(n)$ & $(650)$ & $11.8 \quad(2,919)$ & $<0.001$ & (193) & $12.5 \quad(1,600)$ & 0.361 \\
\hline Surgery 30 days prior $\%(n)$ & $(277)$ & $5.6 \quad(1,390)$ & 0.144 & $(85)$ & $(790)$ & 0.104 \\
\hline
\end{tabular}

$C C I=$ Charlson Comorbidity Index; $C O P D=$ chronic obstructive pulmonary disease; $D V T=$ deep vein thrombosis; $P E=$ pulmonary embolism; $S D=$ standard deviation;

TIA = transient ischemic attack; VTE= venous thromboembolism

each specific type of VTE recurrent event were greater than 3 months. However, $27 \%-38 \%$ of patients who had a recurrent VTE event experienced it within the first month after their index event (DVT only: 37.1\%, PE only: 38.2\%, DVT/ PE: $27.0 \%$, Figure $3 \mathrm{~b}$ ). The proportions of patients who experienced each specific type of recurrent VTE were between $8 \%$ and $9 \%$ within 3 months, between $4 \%$ and $6 \%$ at 6 months, and between 3\% and 5\% within 12 months.

\section{Predictors of VTE Recurrence}

The relationship between VTE recurrence and certain patient characteristics, treatment setting, and demographics are presented in Table 3. Among commercially insured VTE patients, younger age, female gender, and outpatient treatment of index VTE increased the risk of VTE recurrence (lower age in years vs. each incremental year hazard ratio (HR): 0.99, $P<0.001$; female vs. male HR: 1.1, $P=0.007$; inpatient vs. outpatient setting HR: 0.9, $P<0.001)$. Patients who had an index DVT/ PE versus those who had an index DVT only had a greater HR for VTE recurrence (HR: 1.2, $P=0.001$ ). A greater index CCI score was associated with a greater risk for VTE recurrence, such that versus a score of 0 , a score of $1-2$ had an HR of 1.2 $(P<0.001)$, a score of $3-4$ had an HR of $1.5(P<0.001)$, and a score of $\geq 5$ had an HR of $1.8(P<0.001)$. U.S. region of residence did not impact VTE recurrence.

Among Medicare insured patients with a VTE, age and gender did not affect the likelihood of VTE recurrence. Patients who had an index PE only versus those who had an index DVT only had a lower HR for VTE recurrence (HR: 0.8, $P<0.001$ ). A greater CCI score $(>2)$ was associated with a greater risk for VTE recurrence, such that versus a score of 0 , a score of 3-4 had an HR of $1.2(P=0.024)$, and a score of $\geq 5$ had an HR of 1.5 $(P<0.001)$. Additionally, for the Medicare population, the U.S. region where care took place might also affect the probability of VTE recurrence.

\section{Comparison of Health Care Resource Utilization and Associated Payments: Patients with VTE Recurrence Versus Patients without VTE Recurrence}

During the 12-month follow-up period, commercially insured patients with a VTE recurrence associated with a hospitalization or ER visit had higher all-cause and VTE-related health 

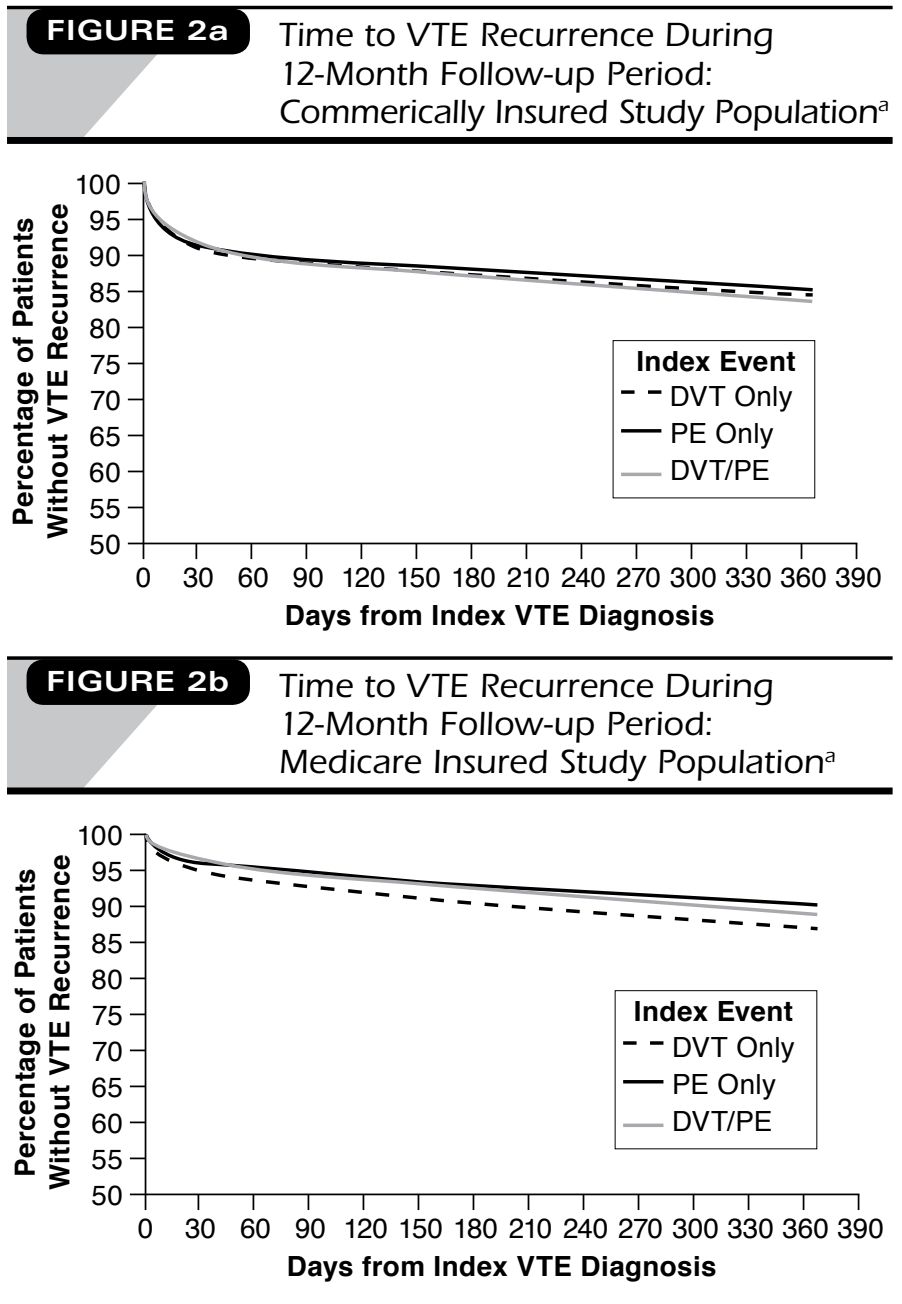

aCommercial population: DVT: $n=17,266 ;$ PE: $n=7,473 ;$ DVT/PE: $n=4,536$; Medicare population: DVT: $n=8,275 ;$ PE: $n=4,260 ; D V T / P E: ~ n=1,974$. $D V T=$ deep vein thrombosis; $P E=$ pulmonary embolism; VTE = venous thromboembolism.

care resource utilization across all evaluated categories than patients without VTE recurrence. This higher resource utilization was reflected in higher associated health care payments (Tables 4 and 5). The primary driver for the increased health care payments for patients with recurrent VTE was a greater use of inpatient care (mean [SD] number of all-cause hospitalizations: 2.1 [1.9] vs. 0.9 [0.9]; all-cause hospital total LOS: 11.9 [17.6] vs. 4.5 [7.2] days; mean number of VTE-related hospitalizations: 1.6 [0.9] vs. 0.7 [0.5]; VTE-related hospital total LOS: 8.4 [10.1] vs. 3.4 [4.3] days; $P<0.001$ for all comparisons). Mean total payments for all-cause hospitalizations $(\$ 47,201$ $[\$ 79,977]$ vs. $\$ 17,225[\$ 34,512], P<0.001)$ and for VTE-related hospitalizations $(\$ 33,594$ [\$50,762] vs. \$12,158 [\$22,003], $P<0.001)$ were consequently greater for patients with recurrent VTE in comparison with patients without recurrent VTE.

\section{FIGURE 3a Monthly Breakdown for all VTE Events During 12-Month Follow-up Period: Commercially Insured Study Population $^{\mathrm{a}}$}

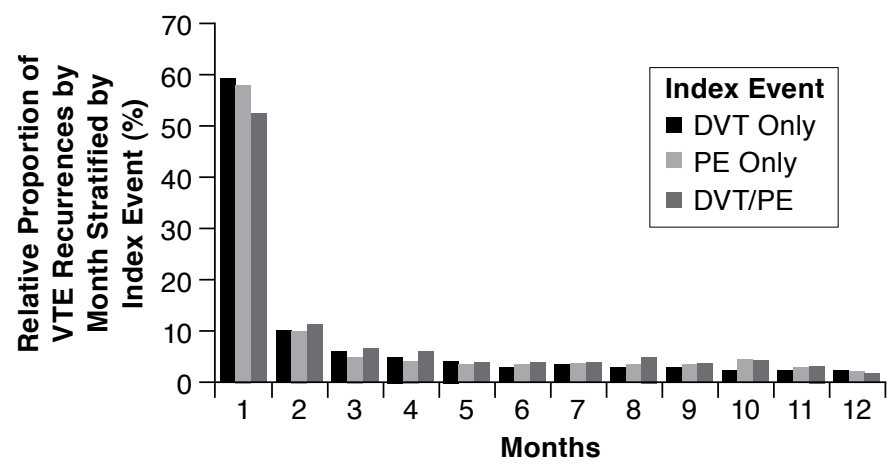

\section{FIGURE 3b Monthly Breakdown for all VTE Events During 12-Month Follow-up Period: Medicare Insured Study Population ${ }^{a}$}

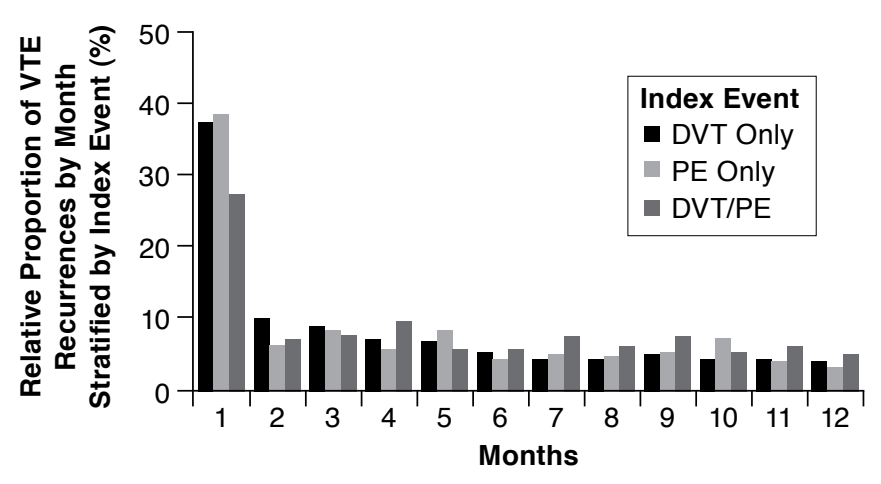

aCommercial population: DVT: $n=2,647$ PE: $n=1,115 ;$ DVT/PE: $n=736$

Medicare population: DVT: $n=1,043$; PE: $n=401$; DVT/PE: $n=211$.

$D V T=$ deep vein thrombosis; $P E=$ pulmonary embolism; VTE $=$ venous thromboembolism.

The number of all-cause and VTE-related outpatient medical service claims, ER claims, and outpatient pharmacy claims were also significantly greater for patients with recurrent VTE. Mean total payments for all health care resource utilization, including inpatient, outpatient medical services, and outpatient pharmacy use were 2.2-fold higher for patients with recurrent VTE relative to patients without recurrent VTE $(\$ 82,110$ $[\$ 106,918]$ vs. $\$ 36,918$ [\$54,852], $P<0.001)$. Additionally, total payments for VTE-related health care resource use were significantly higher for patients with recurrent VTE $(\$ 38,591$ $[\$ 51,479]$ vs. $\$ 15,123[\$ 22,186], P<0.001)$. These results, in terms of higher health care resource utilization and associated payments among VTE recurrent patients, were similar in all 
TABLE 3 Factors Impacting VTE Time to Recurrence (Day)

\begin{tabular}{|c|c|c|c|c|}
\hline Factor & $\begin{array}{c}\text { Hazard } \\
\text { Ratio }\end{array}$ & $\begin{array}{c}\mathrm{CI} \\
\text { Lower }\end{array}$ & $\begin{array}{c}\text { CI } \\
\text { Upper }\end{array}$ & $\begin{array}{c}P \\
\text { Value }\end{array}$ \\
\hline \multicolumn{5}{|l|}{ Commercial population } \\
\hline Age (with each incremental year) & 0.99 & 0.98 & 0.99 & $<0.001$ \\
\hline Gender (female vs. male) & 1.1 & 1.0 & 1.2 & 0.007 \\
\hline \multicolumn{5}{|l|}{ VTE type (vs. DVT only) } \\
\hline PE only & 1.0 & 0.9 & 1.1 & 0.967 \\
\hline DVT/PE & 1.2 & 1.1 & 1.3 & 0.001 \\
\hline Setting (inpatient vs. outpatient) & 0.9 & 0.8 & 0.9 & $<0.001$ \\
\hline \multicolumn{5}{|l|}{ Charlson Comorbidity Index (vs. 0) } \\
\hline $1-2$ & 1.2 & 1.1 & 1.3 & $<0.001$ \\
\hline $3-4$ & 1.5 & 1.3 & 1.6 & $<0.001$ \\
\hline$\geq 5$ & 1.8 & 1.6 & 2.0 & $<0.001$ \\
\hline \multicolumn{5}{|l|}{ Region (vs. South) } \\
\hline North Central & 1.0 & 0.9 & 1.0 & 0.124 \\
\hline Northeast & 1.0 & 0.9 & 1.1 & 0.885 \\
\hline West & 1.0 & 0.9 & 1.1 & 0.705 \\
\hline Unknown & 1.0 & 0.8 & 1.3 & 0.867 \\
\hline
\end{tabular}

\section{Medicare population}

\begin{tabular}{|l|l|l|l|l}
\hline Age (with each incremental year) & 1.0 & 1.0 & 1.0 & 0.846 \\
\hline
\end{tabular}

\begin{tabular}{|l|l|l|l|l}
\hline Gender (female vs. male) & 1.1 & 1.0 & 1.2 & 0.209 \\
\hline
\end{tabular}

VTE type (vs. DVT only)

\begin{tabular}{l|c|c|c|c}
\hline PE only & 0.8 & 0.7 & 0.9 & $<0.001$ \\
\hline DVT/PE & 1.0 & 0.8 & 1.1 & 0.668 \\
\hline Setting (inpatient vs. outpatient) & 0.8 & 0.7 & 0.9 & $<0.001$ \\
\hline
\end{tabular}

Charlson Comorbidity Index (vs. 0)

\begin{tabular}{l|r|r|r|r}
\hline $1-2$ & 1.1 & 1.0 & 1.3 & 0.069 \\
\hline $3-4$ & 1.2 & 1.0 & 1.4 & 0.024 \\
\hline$\geq 5$ & 1.5 & 1.3 & 1.8 & $<0.001$ \\
\hline
\end{tabular}

Region (vs. South)

\begin{tabular}{l|r|r|r|r}
\hline North Central & 1.1 & 1.0 & 1.3 & 0.053 \\
\hline Northeast & 1.4 & 1.2 & 1.7 & $<0.001$ \\
\hline West & 1.5 & 1.3 & 1.8 & $<0.001$ \\
\hline Unknown & 1.2 & 0.7 & 2.1 & 0.511 \\
\hline
\end{tabular}

$C I=$ confidence interval; $D V T=$ deep vein thrombosis; $P E=$ pulmonary embolism; VTE $=$ venous thromboembolism.

respects for the Medicare population, with the exception that differences in total payments for VTE-related outpatient medical services (30 days and 12 months) did not reach statistical significance (Tables 4 and 5).

\section{Comparison of Adjusted Total Health Care Payments: Patients with VTE Recurrence Versus Patients Without VTE Recurrence}

After adjustment for key patient characteristics among cohorts of the commercially insured population, VTE recurrence was associated with 2.2 -fold $(P<0.001)$ and 3.0-fold $(P<0.001)$ higher health care payments for all causes and for VTE, respectively, during the 12-month follow-up period (Table 6). VTE recurrence was associated with 1.8-fold and 2.1-fold higher health care costs for all causes and for VTE-related claims, respectively, during the 30-day period following the index VTE event (Table 6). Absolute differences in health care payments for patients with VTE recurrence versus those without a VTE recurrence during the 12-month follow-up period were $\$ 56,580$ (confidence interval [CI]: $\$ 53,272, \$ 59,888, P<0.05$ ) and $\$ 28,067$ (CI: $\$ 26,748, \$ 29,386, P<0.05)$ for all causes and for VTE-related claims, respectively, and during the 30-day follow-up period were $\$ 14,310$ (CI: $\$ 13,287, \$ 15,333, P<0.05$ ) and $\$ 13,045$ (CI: $\$ 12,184, \$ 13,906, P<0.05)$ for all causes and for VTE-related claims, respectively. These results were similar in the sensitivity regression analysis in which absolute differences in health care payments for patients with VTE recurrence versus those without a VTE recurrence during the 12-month follow-up period were $\$ 69,885$ (CI: $\$ 61,468, \$ 78,302, P<0.05$ ) and $\$ 33,258$ (CI: $\$ 30,051, \$ 36,465, P<0.05)$ for all causes and for VTE-related claims, respectively, and during the 30-day follow-up period were $\$ 17,711$ (CI: $\$ 15,032, \$ 20,390, P<0.05$ ) and $\$ 15,793$ (CI: $\$ 13,609, \$ 17,977, P<0.05)$ for all causes and for VTE-related claims, respectively.

After adjustment for key patient characteristics among cohorts of the Medicare insured population, VTE recurrence was associated with 1.8-fold $(P<0.001)$ and 3.4-fold $(P<0.001)$ higher health care payments for all causes and for VTE, respectively, during the 12-month follow-up period (Table 6). VTE recurrence was associated with 1.6-fold and 1.8-fold higher health care costs for all causes and for VTE-related claims, respectively, during the 30-day period following the index VTE event (Table 6). Absolute differences in health care payments for patients with VTE recurrence versus those without a VTE recurrence during the 12-month follow-up period were $\$ 25,287$ (CI: $\$ 22,167, \$ 28,407, P<0.05$ ) and $\$ 19,788$ (CI: $\$ 18,185, \$ 21,390, P<0.05)$ for all causes and for VTE-related claims, respectively, and during the 30-day follow-up period were $\$ 5,677$ (CI: $\$ 4,755, \$ 6,599, P<0.05$ ) and $\$ 6,114$ (CI: $\$ 5,304, \$ 6,925, P<0.05)$ for all causes and for VTE-related claims, respectively. These results were similar in the sensitivity regression analysis in which absolute differences in health care payments for patients with VTE recurrence versus those without a VTE recurrence during the 12-month followup period were $\$ 26,029$ (CI: $\$ 14,222, \$ 37,836, P<0.05)$ and $\$ 18,630$ (CI: $\$ 13,326, \$ 23,933, P<0.05)$ for all causes and for VTE-related claims, respectively, and during the 30-day follow-up period were $\$ 5,129$ (CI: $\$ 1,878, \$ 8,380, P<0.05$ ) and $\$ 5,562$ (CI: $\$ 2,779, \$ 8,345, P<0.05$ ) for all causes and for VTErelated claims, respectively.

\section{Discussion}

This study shows that despite efforts to reverse the trends of VTE at a national level, ${ }^{6,7}$ recurrence rates are high, resulting in an extensive resource and economic burden to the health care system. Among commercially and Medicare insured patients who experienced an initial VTE event, the 


\section{TABLE 4 All-Cause and VTE-Related Health Care Resource Utilization, 30 Days and} 12 Months Post Initial VTE Event: Commercially and Medicare Insured Patients with VTE Recurrence Versus Patients Without VTE Recurrence

\begin{tabular}{|c|c|c|c|c|c|c|c|}
\hline & \multirow{2}{*}{\multicolumn{2}{|c|}{$\begin{array}{c}\begin{array}{c}\text { Commercial } \\
\text { Study Population }\end{array} \\
\text { Recurrent VTE }\end{array}$}} & \multirow[b]{3}{*}{$\begin{array}{c}P \\
\text { Value }^{\mathrm{a}}\end{array}$} & & \multirow{2}{*}{\multicolumn{2}{|c|}{$\begin{array}{c}\text { Medicare } \\
\text { Study Population } \\
\text { Recurrent VTE }\end{array}$}} & \multirow[b]{3}{*}{$\begin{array}{c}P \\
\text { Value }^{\mathrm{a}}\end{array}$} \\
\hline & & & & & & & \\
\hline & $\begin{array}{c}\text { Yes } \\
(\mathrm{n}=4,498) \\
\text { Mean }[\mathrm{SD}]\end{array}$ & $\begin{array}{c}\text { No } \\
(\mathbf{n}=24,777) \\
\text { Mean }[\mathrm{SD}]\end{array}$ & & & $\begin{array}{c}\text { Yes } \\
(\mathrm{n}=1,655) \\
\text { Mean [SD] }\end{array}$ & $\begin{array}{c}\text { No } \\
(\mathrm{n}=12,854) \\
\text { Mean [SD] }\end{array}$ & \\
\hline \multicolumn{4}{|l|}{ All-cause hospitalizations } & \multicolumn{4}{|l|}{ All-cause hospitalizations } \\
\hline $\begin{array}{l}\text { Within } 30 \text { days post } \\
\text { initial VTE event }\end{array}$ & $1.1 \quad[0.8]$ & $0.7 \quad[0.5]$ & $<0.001$ & $\begin{array}{l}\text { Within } 30 \text { days post } \\
\text { initial VTE event }\end{array}$ & $0.8 \quad[0.6]$ & $0.7 \quad[0.5]$ & $<0.001$ \\
\hline $\begin{array}{l}\text { Within } 12 \text { months post } \\
\text { initial VTE event }\end{array}$ & $2.1 \quad[1.9]$ & $0.9 \quad[0.9]$ & $<0.001$ & $\begin{array}{l}\text { Within } 12 \text { months post } \\
\text { initial VTE event }\end{array}$ & $\begin{array}{ll}1.9 & {[1.3]}\end{array}$ & $1.0 \quad[0.8]$ & $<0.001$ \\
\hline \multicolumn{4}{|c|}{ All-cause total hospital length of stay (days) } & \multicolumn{4}{|c|}{ All-cause total hospital length of stay (days) } \\
\hline $\begin{array}{l}\text { Within } 30 \text { days post } \\
\text { initial VTE event }\end{array}$ & $\begin{array}{ll}5.7 & {[6.7]}\end{array}$ & $3.5 \quad[4.6]$ & $<0.001$ & $\begin{array}{l}\text { Within } 30 \text { days post } \\
\text { initial VTE event }\end{array}$ & $4.3 \quad[5.1]$ & $3.5 \quad[4.1]$ & $<0.001$ \\
\hline $\begin{array}{l}\text { Within } 12 \text { months post } \\
\text { initial VTE event }\end{array}$ & $11.9 \quad[17.6]$ & $\begin{array}{ll}4.5 & {[7.2]}\end{array}$ & $<0.001$ & $\begin{array}{l}\text { Within } 12 \text { months post } \\
\text { initial VTE event }\end{array}$ & $11.3[15.1]$ & [7.1] & $<0.001$ \\
\hline \multicolumn{4}{|c|}{ VTE-related hospitalizations } & \multicolumn{4}{|c|}{ VTE-related hospitalizations } \\
\hline $\begin{array}{l}\text { Within } 30 \text { days post } \\
\text { initial VTE event }\end{array}$ & $1.1 \quad[0.7]$ & $0.7 \quad[0.5]$ & $<0.001$ & $\begin{array}{l}\text { Within } 30 \text { days post } \\
\text { initial VTE event }\end{array}$ & $0.8 \quad[0.6]$ & $0.6 \quad[0.5]$ & $<0.001$ \\
\hline $\begin{array}{l}\text { Within } 12 \text { months post } \\
\text { initial VTE event }\end{array}$ & $\begin{array}{ll}1.6 & {[0.9]}\end{array}$ & $\begin{array}{ll}0.7 & {[0.5]}\end{array}$ & $<0.001$ & $\begin{array}{l}\text { Within } 12 \text { months post } \\
\text { initial VTE event }\end{array}$ & $\begin{array}{ll}1.4 & {[0.8}\end{array}$ & $0.6 \quad[0.5]$ & $<0.001$ \\
\hline \multicolumn{4}{|c|}{ VTE-related total hospital length of stay (days) } & \multicolumn{4}{|c|}{ VTE-related total hospital length of stay (days) } \\
\hline $\begin{array}{l}\text { Within } 30 \text { days post } \\
\text { initial VTE event }\end{array}$ & $5.5 \quad[6.3]$ & $3.4 \quad[4.3]$ & $<0.001$ & $\begin{array}{l}\text { Within } 30 \text { days post } \\
\text { initial VTE event }\end{array}$ & $4.1 \quad[4.5]$ & $\begin{array}{ll}3.4 & {[3.9]}\end{array}$ & $<0.001$ \\
\hline $\begin{array}{l}\text { Within } 12 \text { months post } \\
\text { initial VTE event }\end{array}$ & $8.4 \quad[10.1]$ & $3.4 \quad[4.3]$ & $<0.001$ & $\begin{array}{l}\text { Within } 12 \text { months post } \\
\text { initial VTE event }\end{array}$ & $8.0 \quad[8.5]$ & $3.4 \quad[3.9]$ & $<0.001$ \\
\hline \multicolumn{4}{|c|}{ All-cause outpatient medical service claims } & \multicolumn{4}{|c|}{ All-cause outpatient medical service claims } \\
\hline $\begin{array}{l}\text { Within } 30 \text { days post } \\
\text { initial VTE event }\end{array}$ & $33.6 \quad[25.6]$ & $26.7 \quad[20.0]$ & $<0.001$ & $\begin{array}{l}\text { Within } 30 \text { days post } \\
\text { initial VTE event }\end{array}$ & $23.9[19.5]$ & $18.9[17.4]$ & $<0.001$ \\
\hline $\begin{array}{l}\text { Within } 12 \text { months post } \\
\text { initial VTE event }\end{array}$ & $183.6[155.2]$ & 119 [107.0] & $<0.001$ & $\begin{array}{l}\text { Within } 12 \text { months post } \\
\text { initial VTE event }\end{array}$ & $149.6[115.8]$ & $100.2[89.0]$ & $<0.001$ \\
\hline \multicolumn{4}{|c|}{ VTE-related outpatient medical service claims } & \multicolumn{4}{|c|}{ VTE-related outpatient medical service claims } \\
\hline $\begin{array}{l}\text { Within } 30 \text { days post } \\
\text { initial VTE event }\end{array}$ & $14.1 \quad[15.0]$ & $11.2 \quad[11.9]$ & $<0.001$ & $\begin{array}{l}\text { Within } 30 \text { days post } \\
\text { initial VTE event }\end{array}$ & $8.5 \quad[10.1]$ & $6.2 \quad[8.2]$ & $<0.001$ \\
\hline $\begin{array}{l}\text { Within } 12 \text { months post } \\
\text { initial VTE event }\end{array}$ & $38.4 \quad[35.0]$ & $26.3[25.1]$ & $<0.001$ & $\begin{array}{l}\text { Within } 12 \text { months post } \\
\text { initial VTE event }\end{array}$ & $23.1[26.4]$ & $13.7[19.1]$ & $<0.001$ \\
\hline \multicolumn{4}{|c|}{ All-cause emergency room claims } & \multicolumn{4}{|c|}{ All-cause emergency room claims } \\
\hline $\begin{array}{l}\text { Within } 30 \text { days post } \\
\text { initial VTE event }\end{array}$ & $2.0 \quad[5.2]$ & $0.8 \quad[3.6]$ & $<0.001$ & $\begin{array}{l}\text { Within } 30 \text { days post } \\
\text { initial VTE event }\end{array}$ & $1.0 \quad[2.9]$ & $0.4 \quad[2.0]$ & $<0.001$ \\
\hline $\begin{array}{l}\text { Within } 12 \text { months post } \\
\text { initial VTE event }\end{array}$ & $\begin{array}{ll}6.2 & {[15.6]}\end{array}$ & $2.2 \quad[8.5]$ & $<0.001$ & $\begin{array}{l}\text { Within } 12 \text { months post } \\
\text { initial VTE event }\end{array}$ & {$[7.6]$} & $\begin{array}{ll}.4 & {[4.2]}\end{array}$ & $<0.001$ \\
\hline \multicolumn{4}{|c|}{ VTE-related emergency room claims } & \multicolumn{4}{|c|}{ VTE-related emergency room claims } \\
\hline $\begin{array}{l}\text { Within } 30 \text { days post } \\
\text { initial VTE event }\end{array}$ & $\left.\begin{array}{ll}1.2 & {[3.8}\end{array}\right]$ & {$[2.4]$} & $<0.001$ & $\begin{array}{l}\text { Within } 30 \text { days post } \\
\text { initial VTE event }\end{array}$ & $0.6 \quad[2.1]$ & $0.2 \quad[1.2]$ & $<0.001$ \\
\hline $\begin{array}{l}\text { Within } 12 \text { months post } \\
\text { initial VTE event }\end{array}$ & $\begin{array}{ll}.7 & {[4.6]}\end{array}$ & {$[2.4]$} & $<0.001$ & $\begin{array}{l}\text { Within } 12 \text { months post } \\
\text { initial VTE event }\end{array}$ & $1.0 \quad[2.5]$ & {$[1.2]$} & $<0.001$ \\
\hline \multicolumn{4}{|c|}{ All-cause outpatient pharmacy claims } & \multicolumn{4}{|c|}{ All-cause outpatient pharmacy claims } \\
\hline $\begin{array}{l}\text { Within } 30 \text { days post } \\
\text { initial VTE event }\end{array}$ & $6.9 \quad[3.9]$ & {$[3.4]$} & $<0.001$ & $\begin{array}{l}\text { Within } 30 \text { days post } \\
\text { initial VTE event }\end{array}$ & $\begin{array}{ll}6.6 & {[3.7]}\end{array}$ & $6.4 \quad[3.8]$ & 0.075 \\
\hline $\begin{array}{l}\text { Within } 12 \text { months post } \\
\text { initial VTE event }\end{array}$ & $45.9 \quad[33.5]$ & $35.8 \quad[28.4]$ & $<0.001$ & $\begin{array}{l}\text { Within } 12 \text { months post } \\
\text { initial VTE event }\end{array}$ & $53.1 \quad[30.3]$ & $48.1 \quad[30.0]$ & $<0.001$ \\
\hline \multicolumn{4}{|c|}{ VTE-related outpatient pharmacy claims } & \multicolumn{4}{|c|}{ VTE-related outpatient pharmacy claims } \\
\hline $\begin{array}{l}\text { Within } 30 \text { days post } \\
\text { initial VTE event }\end{array}$ & $\begin{array}{ll}2.7 & {[1.5]}\end{array}$ & {$[1.5]$} & 0.825 & $\begin{array}{l}\text { Within } 30 \text { days post } \\
\text { initial VTE event }\end{array}$ & $2.2 \quad[1.2]$ & {$[1.3]$} & 0.440 \\
\hline $\begin{array}{l}\text { Within } 12 \text { months post } \\
\text { initial VTE event }\end{array}$ & $9.8 \quad[5.3]$ & $8.5 \quad[4.9]$ & $<0.001$ & $\begin{array}{l}\text { Within } 12 \text { months post } \\
\text { initial VTE event }\end{array}$ & $\begin{array}{ll}8.7 & {[5.3]}\end{array}$ & {$[5.2]$} & $<0.001$ \\
\hline
\end{tabular}



with VTE Recurrence Versus Patients Without VTE Recurrence

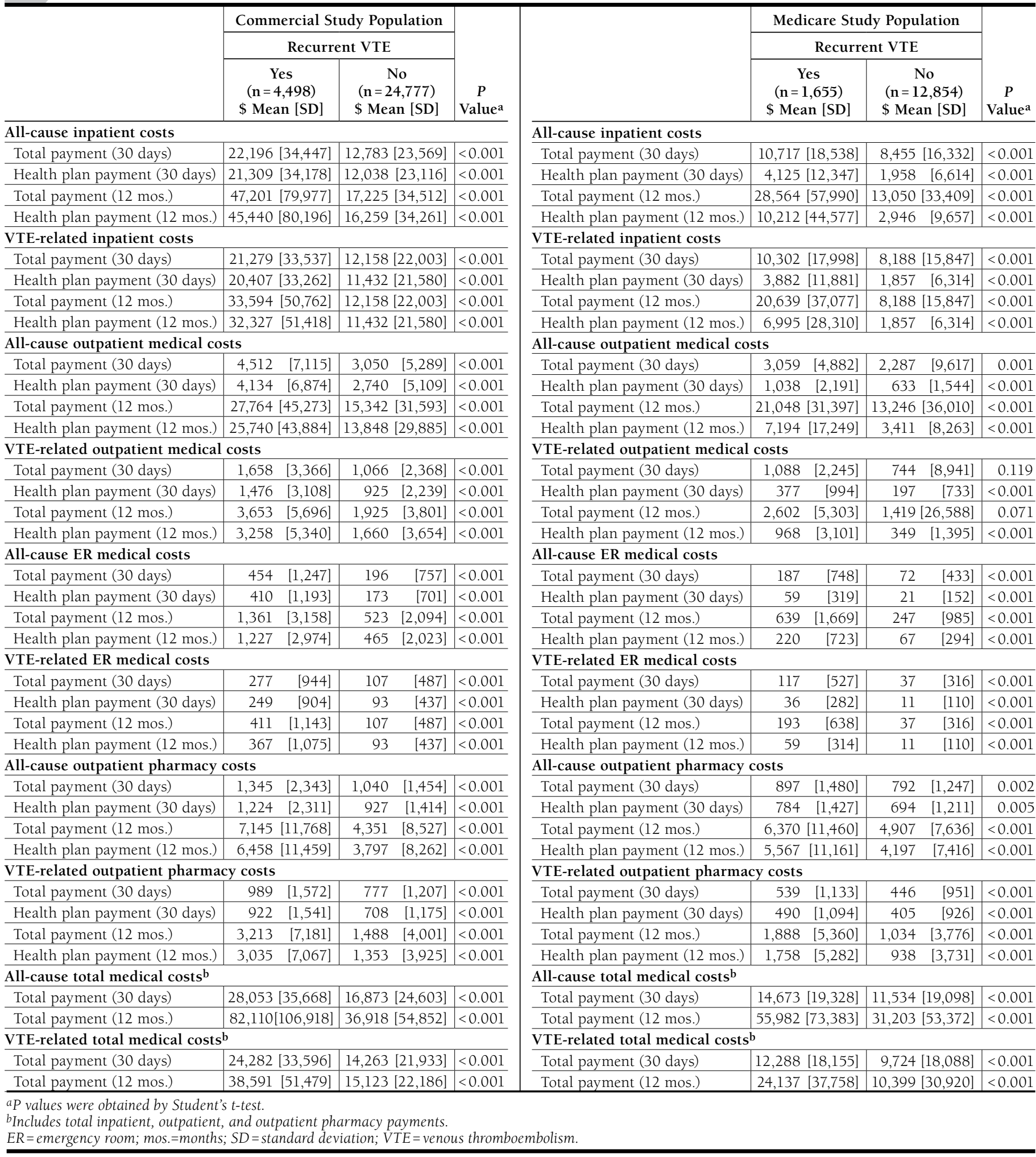




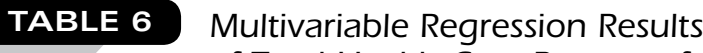

of Total Health Care Payment for

All-Cause and VTE-Related Health

Care Resource Use During 30-Day

and 12-Month Follow-up Periods

\begin{tabular}{l|l|l|l|l}
\hline & Cost Ratio & CI Lower & CI Upper & $P$ Value \\
\hline
\end{tabular}

Commercial population

\begin{tabular}{|c|c|c|c|c|}
\hline \multicolumn{5}{|l|}{30 days } \\
\hline All cause & 1.8 & 1.8 & 1.9 & $<0.001$ \\
\hline VTE-related & 2.1 & 2.0 & 2.1 & $<0.001$ \\
\hline \multicolumn{5}{|l|}{12 months } \\
\hline All cause & 2.2 & 2.2 & 2.3 & $<0.001$ \\
\hline VTE-related & 3.0 & 3.0 & 3.1 & $<0.001$ \\
\hline \multicolumn{5}{|c|}{ Medicare population } \\
\hline \multicolumn{5}{|l|}{30 days } \\
\hline All cause & 1.6 & 1.5 & 1.6 & $<0.001$ \\
\hline VTE-related & 1.8 & 1.8 & 1.9 & $<0.001$ \\
\hline \multicolumn{5}{|l|}{12 months } \\
\hline All cause & 1.8 & 1.7 & 1.9 & $<0.001$ \\
\hline VTE-related & 3.4 & 3.3 & 3.6 & $<0.001$ \\
\hline
\end{tabular}

frequencies of VTE recurrence ranged from $11.4 \%$ to $15.4 \%$. These rates of VTE recurrence are substantially higher than the 3.6\% rate of hospital-documented recurrent VTE recently reported by Lefebvre et al. (2012). ${ }^{15}$ One explanation for the greater VTE recurrence rates among our study populations is that we included ER visits in our definition of an acute VTE event, which were not included in the Lefebvre et al. study. ${ }^{15}$ VTE recurrence rates in the commercial and Medicare populations were similar to the $14.3 \%$ rate of hospital readmission for VTE among patients with VTE as a secondary diagnosis reported by Spyropoulos and Lin. ${ }^{10}$ Other less recent studies have reported VTE recurrence rates to range between $7.0 \%$ and $14.0 \%{ }^{11}$ Even in patients who only experienced an initial event with no recurrence, VTE-related care and associated payments (commercial: $\$ 15,123$ per patient per year; Medicare: $\$ 10,399$ per patient per year) were substantial. These results are in line with that of Spyropoulos and Lin in which total VTE-related health care costs in 1 year following a single VTE event were between $\$ 7,594$ and $\$ 27,909$, depending on whether the VTE event was DVT, PE, or DVT/PE and whether it was for a primary or secondary diagnosis of VTE. ${ }^{10}$ Payments for overall health care resource use, including inpatient, outpatient, and outpatient pharmacy claims were markedly higher for patients with VTE recurrence ( 2- to 3-fold) in comparison with patients without a VTE recurrence. The mean total health care payment for any reason for commercially insured patients with VTE recurrence was $\$ 82,110$ annually with $47.0 \%$ attributed to VTE-related care. Medicare patients with a recurrent VTE event incurred less costs than those insured commercially, with a mean total payment of \$55,982 annually with $43.0 \%$ attributed to VTE-related care. Multivariable regression analyses that were conducted to test the validity of the effect of VTE recurrence status on the 30-day and 12-month all-cause and VTE-related health care costs further confirmed that VTE recurrence is associated with a substantial incremental cost burden.

The 12-month incidence rate of VTE recurrence was higher for the commercially insured patients than Medicare insured patients. As the mean age for the commercially insured VTE patients was much younger than Medicare VTE patients, these results seem counterintuitive, as age is a known risk factor for VTE. However, previous studies have reported that VTE recurrence is unrelated to age. ${ }^{16,17}$ In fact, although we found age to be inversely related to the risk of VTE recurrence among commercially insured patients in our analysis, it was not a significant predictor for VTE recurrence in the Medicare study population. Medicare enrollees included in the MarketScan database have employer-sponsored supplemental insurance, and it is plausible that they may have access to better VTE treatment resulting in lower risk of VTE recurrence. Among the Medicare study population, VTE recurrence rate was affected by the U.S. region in which VTE care took place, which demonstrates that, among the Medicare insured population, VTE recurrence rate appears sensitive to variations in the standards of care. Medicare insured patients may also be more adherent to warfarin therapy than commercially insured patients, since they seek medical care more often due to their higher comorbidity burden than younger patients. It is possible that there was a higher prevalence of VTE recurrence cases associated with the use of oral contraceptives in the younger commercially insured female patients. On the other hand, Spencer et al. (2008) did find that older patients were less likely to have unprovoked VTE than younger patients, and unprovoked VTE represents a greater risk for VTE recurrence than provoked VTE ${ }^{17}$ In the absence of further clinical information, we were unable to obtain a complete clinical profile of study patients or to confirm the causes of VTE recurrences. Further research is needed to confirm our study findings and understand the risk profiles for recurrent VTE events in these 2 study populations.

Based on the results of our study, patients initially treated in the inpatient setting had a lower VTE recurrence rate than those treated in the outpatient setting. This may indicate that patients might have received better treatment for VTE in the inpatient setting. This is of concern, since a focus of health care reform is to switch more to outpatient versus inpatient treatment/management. Therefore, it will be important in future studies to further assess the differences and similarities of the standards of care for VTE patients in the outpatient versus inpatient settings.

\section{Limitations}

As in all studies using retrospective database claims analyses, there is the potential for bias in this study. We attempted to alleviate some potential bias by comparing patient groups in 
which both had experienced an initial VTE event. Additionally, we further used multivariable regression analyses that controlled for differences in many patient characteristics to confirm the burden of VTE recurrences. However, there may be other potential confounding variables that were not measured and controlled for in this study, such as bleeding risk. Due to constraints within the databases, we were unable to differentiate between an outpatient office visit for a VTE recurrence and an outpatient office visit for a follow-up to a VTE event; therefore, VTE recurrence was evaluated only in the inpatient or ER setting during the follow-up period. This may have led to an underestimation of VTE recurrence frequency, since VTE is often diagnosed in an outpatient setting (i.e., physician's office). ${ }^{18}$ Additionally, to rule out patients who were followed up in the inpatient setting soon after the index VTE diagnosis, patients admitted to the hospital or ER settings within 2 days of the index VTE event were not included in the patient population with VTE recurrence. Also, since we did not evaluate all VTE-related complications, such as thrombocytopenia, pulmonary hypertension, and post-thrombotic syndrome. Therefore, health care resource utilization and associated payments categorized as VTE-related may have been underestimated, although they were captured in the incremental costs of allcause health care utilization and payments. The MarketsScan databases consist of claims submitted by health care providers on behalf of individuals who are beneficiaries, and such claims are subject to possible coding errors, coding for the purpose of rule-out rather than actual disease, and undercoding, either by the health care provider or due to limitations imposed by the database. In addition, the presence of a diagnostic code does not always definitively indicate the presence of a condition, and coding of secondary conditions may be less reliable. Since patients with acute and chronic VTE disease, which may more likely have received a secondary diagnosis code, were not differentiated in this study, the results may or may not be generalized to these subsets of patients with VTE disease, and further study is warranted. Lastly, the MarketScan databases are based on a large convenience sample, and since the sample is not random, it may fail to generalize well to other populations with alternate health care coverage such as Medicaid.

\section{Conclusions}

Even with anticoagulant treatment, VTE recurrence ranged from $11.4 \%$ to over $15 \%$ with the majority of recurrences occurring within 30 days of the initial VTE event. VTE recurrence is associated with substantial health care resource utilization, primarily inpatient care, resulting in high health care costs. Strategies to improve treatment of patients with VTE are needed to lessen the health care and economic burdens of recurrent VTE.

\section{Authors}

J. LIN, PhD, is Managing Director, and M. LINGOHR-SMITH, PhD, is Research Investigator, Novosys Health, Flemington, New Jersey. R. PREBLICK, PharmD, MPH, is Director, and W.J. Kwong, PharmD, PhD, is Senior Director, Health Economics \& Outcomes Research, Daiichi Sankyo, Inc., Parsippany, New Jersey.

AUTHOR CORRESPONDENCE: J. Lin, PhD, Managing Director, Novosys Health, 7 Crestmont Ct., Flemington, NJ 08822.

Tel.: 908.720.2910; Fax: 413.403.3955;

E-mail:jay.lin@novosyshealth.com.

\section{DISCLOSURES}

This research was funded by Daiichi Sankyo, Inc. Lin and Lingohr-Smith are employees of Novosys Health, which has received research funding from Daiichi Sankyo, Inc., in connection with conducting this study and development of this manuscript. Preblick and Kwong are employees of Daiichi Sankyo, Inc.

Concept and design were contributed by Preblick, Lingohr-Smith, Kwong, and Lin. Lin and Lingohr-Smith were primarily responsible for data collection, with assistance from Preblick and Kwong. Data interpretation was done by Preblick, Kwong, Lin, and Lingohr-Smith. Lingohr-Smith was primarily responsible for writing the manuscript, with assistance from Lin, Preblick, and Kwong. The manuscript was revised by Preblick, Kwong, Lin, and Lingohr-Smith.

\section{REFERENCES}

1. Lindblad B, Sternby NH, Bergqvist D. Incidence of venous thromboembolism verified by necropsy over 30 years. BMJ. 1991;302(6778):709-11. Available at: http://www.ncbi.nlm.nih.gov/pmc/articles/PMC1669118/. Accessed October 8, 2013.

2. Sandler DA, Martin JF. Autopsy proven pulmonary embolism in hospital patients: are we detecting enough deep vein thrombosis? JR Soc Med. 1989;82(4):203-05. Available at: http://www.ncbi.nlm.nih.gov/pmc/articles/ PMC1292084/. Accessed October 8, 2013.

3. Alikhan R, Peters F, Wilmott R, Cohen AT. Fatal pulmonary embolism in hospitalised patients: a necropsy review. J Clin Pathol. 2004;57(12):125457. Available at: http://www.ncbi.nlm.nih.gov/pmc/articles/PMC1770519/. Accessed October 8, 2013.

4. Centers for Disease Control and Prevention. Venous thromboembolism in adult hospitalizations-United States, 2007-2009. MMWR Morb Mortal Wkly Rep. 2012;61(22):401-04. Available at: http://www.cdc.gov/mmwr/preview/ mmwrhtml/mm6122al.htm. Accessed October 8, 2013.

5. Mahan CE, Borrego ME, Woersching AL, et al. Venous thromboembolism annualised United States models for total, hospital-acquired and preventable costs utilising long-term attack rates. Thromb Haemost. 2012;108(2):291-302.

6. Centers for Medicare and Medicaid Services. Partnership for patients. Available at: http://partnershipforpatients.cms.gov/about-the-partnership/ what-is-the-partnership-about/lpwhat-the-partnership-is-about.html. Accessed October 8, 2013.

7. U.S. Department of Health and Human Services. The Surgeon General's call to action to prevent deep vein thrombosis and pulmonary embolism. 2008. Available at: http://www.surgeongeneral.gov/library/calls/deepvein/ call-to-action-on-dvt-2008.pdf. Accessed October 8, 2013.

8. Ramzi DW, Leeper KV. DVT and pulmonary embolism: Part II. Treatment and prevention. Am Fam Physician. 2004;69(12):2841-48. Available at: http:// www.aafp.org/afp/2004/0615/p2841.html. Accessed October 8, 2013. 
9. Kearon C, Akl EA, Comerota AJ, et al. Antithrombotic therapy for VTE disease: Antithrombotic Therapy and Prevention of Thrombosis, 9th ed: American College of Chest Physicians Evidence-Based Clinical Practice Guidelines. Chest. 2012;141(2 Suppl):e419S-94S. Available at: http://journal publications.chestnet.org/article.aspx?articleid $=1159520$. Accessed October 8, 2013

10. Spyropoulos AC, Lin J. Direct medical costs of venous thromboembolism and subsequent hospital readmission rates: an administrative claims analysis from 30 managed care organizations. J Manag Care Pharm. 2007;13(6):47586. Available at: http://www.amcp.org/data/jmcp/pages\%20475-86.pdf.

11. White RH. The epidemiology of venous thromboembolism. Circulation. 2003;107:I4-18. Available at: http://circ.ahajournals.org/content/107/23_ suppl_1/I-4.long. Accessed October 8, 2013.

12. Bullano MF, Willey V, Hauch O, Wygant G, Spyropoulos AC, Hoffman L. Longitudinal evaluation of health plan cost per venous thromboembolism or bleed event in patients with a prior venous thromboembolism during hospitalization. J Manag Care Pharm. 2005;11(8):663-73. Available at: http:// www.amcp.org/WorkArea/DownloadAsset.aspx?id=7269.

13. Charlson ME, Pompei P, Ales KL, MacKenzie CR. A new method of classifying prognostic comorbidity in longitudinal studies: development and validation. J Chronic Dis. 1987;40(5):373-83.
14. Elixhauser A, Steiner C, Harris DR, Coffey RM. Comorbidity measures for use with administrative data. Med Care. 1998;36(1):08-27.

15. Lefebvre P, Laliberté F, Nutescu EA, et al. All-cause and potentially disease-related health care costs associated with venous thromboembolism in commercial, Medicare, and Medicaid beneficiaries. J Manag Care Pharm. 2012;18(5):363-74. Available at: http://amcp.org/WorkArea/DownloadAsset. aspx?id=15288.

16. Eischer L, Eichinger S, Kyrle PA. Age at first venous thromboembolism and risk of recurrence: a prospective cohort study. Medicine (Baltimore). 2009;88(6):366-70

17. Spencer FA, Gore JM, Lessard D, et al. Venous thromboembolism in the elderly. A community-based perspective. Thromb Haemost. 2008;100(5):78085. Available at: http://www.ncbi.nlm.nih.gov/pmc/articles/PMC2658648/. Accessed October 8, 2013.

18. Spencer FA, Lessard D, Emery C, Reed G, Goldberg RJ. Venous thromboembolism in the outpatient setting. Arch Intern Med. 2007;167(14):147175. Available at: http://www.ncbi.nlm.nih.gov/pmc/articles/PMC2762787/. Accessed October 8, 2013. 